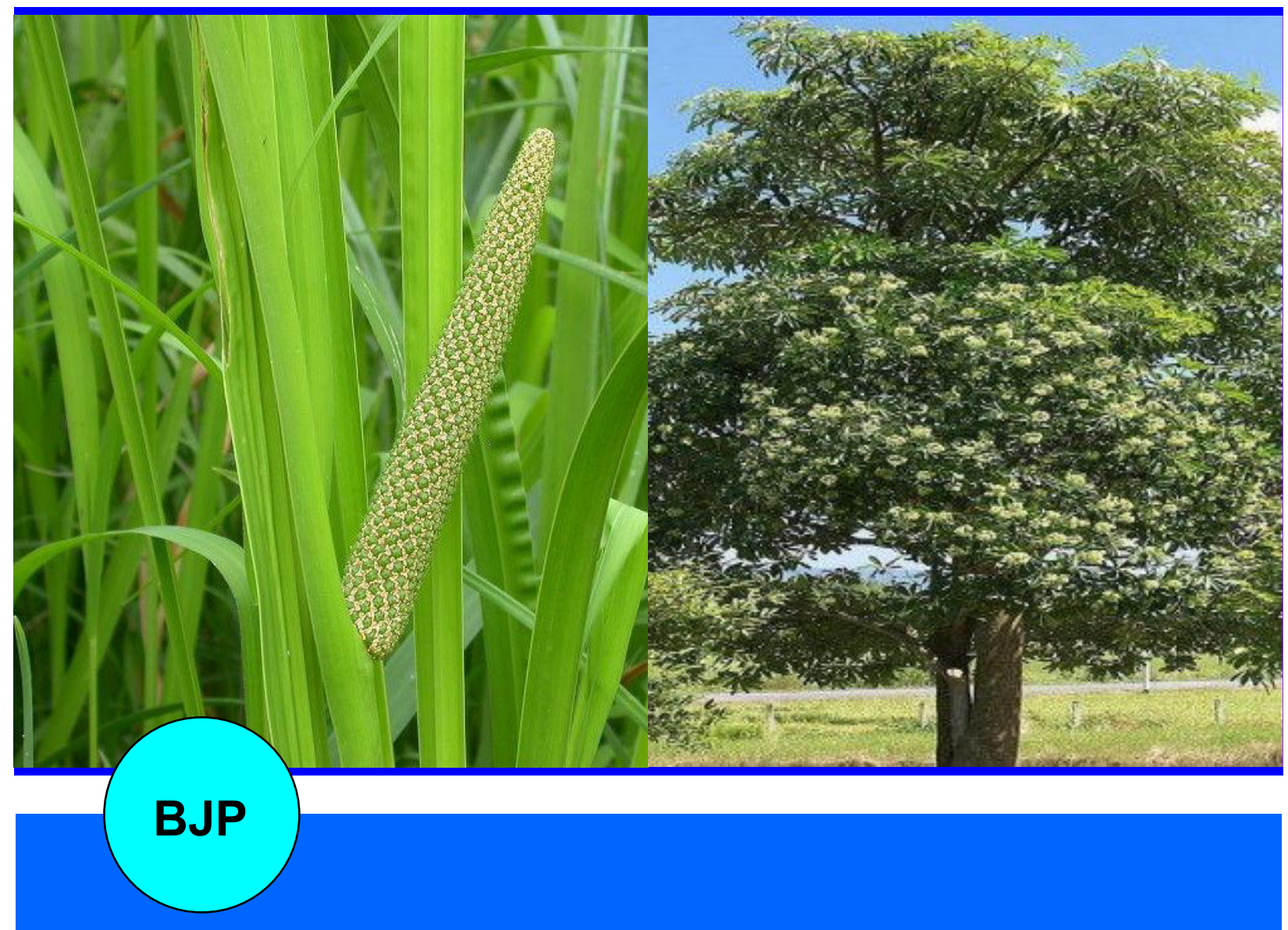

Bangladesh Journal of Pharmacology

Research Article

\title{
Evaluation of antileishmanial activity of plants used in Indian traditional medicine
}




\section{Evaluation of antileishmanial activity of plants used in Indian traditional medicine}

\section{Arushdeep Sidana and Umar Farooq}

Molecular and Immuno-parasitology Laboratory, Faculty of Biotechnology, Shoolini University, Solan 173 229, Himachal Pradesh, India.

\begin{tabular}{lr}
\hline Article Info & \\
\hline Received: & 25 March 2015 \\
Accepted: & 2 May 2015 \\
Available Online: & 15 May 2015 \\
DOI: $10.3329 /$ bjp.v10i2.22674
\end{tabular}

Cite this article:

Sidana A, Farooq U. Evaluation of antileishmanial activity of plants used in Indian traditional medicine. Bangladesh J Pharmacol. 2015; 10: 423-26.

\begin{abstract}
The present study was aimed at in vitro antileishmanial screening of 10 plants used in the traditional medicine in India. MTT method was used to evaluate the cell death after application of $100,250,350$ and $500 \mu \mathrm{g} / \mathrm{mL}$ of the methanolic extracts followed by incubation for 24 hours at $25^{\circ} \mathrm{C}$. Methanolic leaf extracts of Acorus calamus, Alstonia scholaris and Berberis aristata showed significant antileishmanial activity at a concentration of $500 \mu \mathrm{g} / \mathrm{mL}$. In order to identify the antileishmanial compounds present in the active extracts of the screened plants, an LC-MS analysis of the tested extracts was carried out. The active extracts revealed the presence of some natural products with known antileishmanial activity along with other compounds. The present study suggests that the active plant extracts may be processed to isolate the compounds that may further be screened for their antileishmanial potential.
\end{abstract}

\section{Introduction}

Leishmaniasis is a current public health concern and is among the five parasitic diseases of high social impact world-wide (de Albuquerque Melo et al., 2014). Despite the existence of several antileishmanial drugs including pentavalent antimonials, amphotericin B and pentamidine, none is fully effective due to toxicity, variable efficacy, long-term parenteral administration and emergence of drug resistance (Camacho et al., 2003; Croft et al., 2006). The drugs which are effective to some extent are very expensive and are usually unavailable in the endemic areas of the disease. People in rural areas of developing countries have been using traditional medicinal plants as oral decoctions for the treatment of visceral leishmaniasis and the paste form for topical application for curing skin infections like cuta-neous leishmaniasis (Chan-Bacab and PenaRodriguez 2001). In the present study, ten of the traditionally used medicinal plants were selected on the basis of their ethno-botanical reports and were screened for the anti-leishmanial potential against $L$. donovani promastigotes.

\section{Materials and Methods}

\section{Plant material and preparation of extracts}

Authenticated plants were obtained from Y.S. Parmar University of Horticulture and Forestry, Nauni, H.P., India. Plant parts included in the study were dried under shade and pulverized to yield coarse powder. The powder of each plant was then extracted in methanol using hot soxhlet extraction for 24 hours. The extracts were concentrated under reduced pressure using rotary evaporator and the concentrated extracts were further dried in a desiccator using calcium chloride as desiccant. Dried extracts were weighed to obtain the percentage yield and stored in air tight bottles at $4^{\circ} \mathrm{C}$ until use.

\section{Parasite stock culture}

Axenic culture of L. donovani (LdMIPL-1) was maintained at $25^{\circ} \mathrm{C}$ in RPMI 1640 (Himedia, India) medium supplemented with $10 \%$ heat inactivated Fetal Bovine Serum (FBS) (Himedia, India), streptomycin $(150 \mu \mathrm{g} / \mathrm{mL})$, penicillin $\mathrm{G}(100 \mu \mathrm{g} / \mathrm{mL})$ and gentamycin 
$(150 \mu \mathrm{g} / \mathrm{mL})$ at $\mathrm{pH} 7.2$.

\section{Antileishmanial assay}

For antileishmanial activity, pro-mastigotes of $L$. donovani were sub-cultured in Schneider's Insect Medium (Himedia, India) supplemented with 10\% heat inactivated FBS, streptomycin $(150 \mu \mathrm{g} / \mathrm{mL})$, penicillin $\mathrm{G}$ $(100 \mu \mathrm{g} / \mathrm{mL})$ and gentamycin $(150 \mu \mathrm{g} / \mathrm{mL})$. The antileishmanial screening was performed in 96-well flat bottom tissue culture plates (Corning Life Sciences, USA). One hundred microliters of cell suspension containing $2 \times 10^{6}$ to $3 \times 10^{6}$ cells $/ \mathrm{mL}$ was poured in each well of the plate. Four different concentrations of the methanolic extracts i.e. 100, 250, 350 and $500 \mu \mathrm{g} /$ $\mathrm{mL}$, dissolved in dimethyl sulfoxide $(<0.025 \% \mathrm{v} / \mathrm{v})$, were added to the culture. The plates were then incubated at $25^{\circ} \mathrm{C}$ for 24 hours. Amphotericin B and sodium stibugluconate were used as positive controls and cell suspension with $0.02 \%$ DMSO was used as a negative control. Inhibition of the promastigotes was assessed by measuring the cleavage of $10 \mathrm{mg} / \mathrm{mL}$ of MTT [3-(4.5-dimethylthiazol-2-yl)-2.5-diphenyl tetrazolium bromi-de] (Mossman, 1983). The absorbance was measured by using ELISA plate reader (BioTek, USA) at $595 \mathrm{~nm}$. Percent growth inhibition was calculated by the following formula:

$\%$ of inhibition $=\frac{\mathrm{OD} \text { control }-\mathrm{OD} \text { treated }}{\mathrm{OD} \text { control }} \times 100$

\section{LC-MS analysis of the active extracts}

The LC-MS analysis was carried out on X-Bridge C18 (2.1 $\times 50 \mathrm{~mm}, 3.5 \mu \mathrm{m})$ column fitted to an LC-MS 6320 Ion Trap instrument (Agilent Technologies). A gradient of 50 to $100 \%$ acetonitrile in $25 \mathrm{mM}$ ammonium acetate buffer was used as a mobile phase and the flow rate was set at $0.4 \mathrm{~mL} / \mathrm{min}$. Injection volume was $5 \mu \mathrm{L}$.

\section{Statistical analysis}

All the assays were performed in triplicate with at least two replicates of each concentration tested. The results were expressed as mean \pm standard error of the mean. The statistical analysis of the differences between mean values obtained was done by means of one-way ANOVA using GraphPad Prism 5.02 software. A value of $p<0.05$ was considered significant.

\section{Results}

A total of ten methanolic extracts of medicinal plants used in traditional medicine in India were evaluated for their antileishmanial potential using MTT reduction assay (Table I). Methanolic extracts of Acorus calamus leaves, Alstonia scholaris leaves and Berberis aristata leaves showed significant leishmanicidal activity against $L$. donovani promastigotes. The most active extract was $A$. scholaris at a concentration of $500 \mu \mathrm{g} / \mathrm{mL}$. It inhibited $40.3 \%$ of $L$. donovani promastigotes within 24 hours of incubation. The inhibition was concentration dependent as the inhibition increased with the increase in concentration of the extract. Leaf extract of B. aristata at a concentration of $500 \mu \mathrm{g} / \mathrm{mL}$ showed $36.2 \%$ inhibition whereas A. calamus showed $35.6 \%$ inhibition (Figure 1).

The three active extracts viz. Acorus calamus, Alstonia scholaris and Berberis aristata were subjected to LC-MS analysis so as to identify the antileishmanial compounds present in the extracts. In the case of $A$. calamus, the major chromatographic peak eluted at 5.7 min and presented a base peak at $m / z 210[\mathrm{M}+2]^{+}$in the mass spectrum. The molecular ion peak, however, was detected at $m / z \quad 208[\mathrm{M}]^{+}$. This molecular weight matched with that of the three major phenyl propanoids namely $a_{-}, \beta$ - and $\gamma$-asarones (1-3) reported from the plant (Figure 2). The chromatogram of $A$. scholaris revealed the presence of several overlapping peaks attributed to alkaloids. The MS analysis indicated the presence of picrinine (eluted at $6.0 \mathrm{~min}, \mathrm{~m} / \mathrm{z} 337[\mathrm{M}-1]^{+}$, 4 ) and nareline and/or tetrahydroalstonine (eluted at

Table I

Details of the plants used for antileishmanial activity evaluation

\begin{tabular}{|llllr|}
\hline Botanical name & Family & Local Name & Part used & Extractive value (\%) \\
\hline Acorus calamus & Acoraceae & Boiye & Leaf & 7.1 \\
Alstonia scholaris & Apocynaceae & Chitvan & Leaf & 9.4 \\
Andrographis paniculata & Acanthaceae & Kalmegh & Stem & 11.2 \\
Berberis aristata & Berberidaceae & Kashmal & Leaf & 10.8 \\
Butea monosperma & Fabaceae & Palash & Flower & 18.2 \\
Eclipta prostrata & Asteraceae & Bhringraja & Whole plant & 9.4 \\
Gloriosa superba & Colchicaceae & Kalihari & Tuber & 2.5 \\
Juglans regia & Juglandaceae & Akhrot & Bark & 10.9 \\
Mesua ferrea & Calophyllaceae & Nagkesara & Flower bud & 14.7 \\
Tinospora cordifolia & Menispermaceae & Guduchi & Stem & 6.4 \\
\hline
\end{tabular}




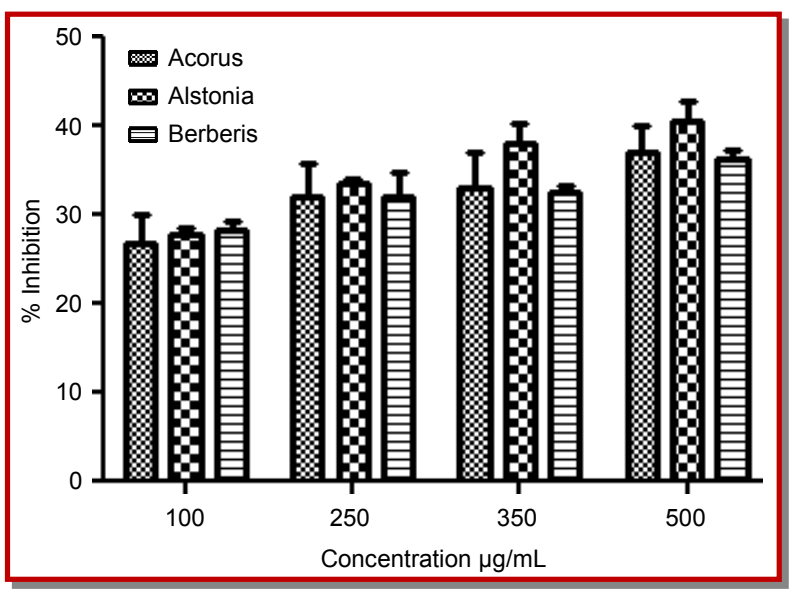

Figure 1: Percentage inhibition of L. donovani promastigotes in the presence of methanolic leaf extracts of Acorus calamus, Alstonia scholaris and Berberis aristata $(100-500 \mu \mathrm{g} / \mathrm{mL})$. Each data value represents mean \pm SEM of at least three experiments performed in duplicate

$\left.6.6 \mathrm{~min}, \mathrm{~m} / \mathrm{z} 351[\mathrm{M}-1]^{+}, 5 \mathrm{a} / \mathrm{b}\right)$. The major peak in the chromatogram of $B$. aristata extract eluted at $4.6 \mathrm{~min}$ and presented an $[\mathrm{M}]^{+}$peak at $\mathrm{m} / z$ 336. This molecular weight corresponds to berberine (6), a major compound reported from this plant. Epiberberine (7), another compound with similar molecular structure, also corresponds to this molecular weight. A small peak in the chromatogram, eluting at $5.4 \mathrm{~min}$, gave an $[\mathrm{M}]^{+}$ion at $m / z 352$ in the mass spectrum. This molecular ion could be attributed to berberastine (8). Figure 2 presents the structures of compounds 1-8.

\section{Discussion}

Out of the ten crude methanolic extracts, three have shown significant leishmanicidal activity by inhibiting $35-40 \%$ promastigotes within 24 hours of application. These active extracts were further analysed by LC-MS to determine the presence of various components. The major compounds present in the extract of Acorus calamus were isomeric phenyl propanoids (1-3). This is the first report of the antileishmanial activity of this plant. The ethanolic extract of the stem of Alstonia scholaris has been previously screened for its antileishmanial activity against some strains of L. donovani (Rocha et al., 2005). However, no study so far has reported the antileishmanial activity of the compounds detected in the extract viz. picrinine (4) nareline (5a) and tetrahydro -alstonine $(5 \mathbf{b})$. In the case of $B$. aristata, the chief alkaloid i.e. berberine (6) is used in folk remedies for the treatment of cutaneous leishmaniasis. Other structurally related alkaloids have also been found active against Leishmania (Chan-Bacab and PenaRodriguez, 2001). Further studies are required to establish the antileishmanial potential of these compounds.

\section{Acknowledgement}

The authors are thankful to the management of Shoolini University, Solan for providing the required facilities and resources to carry out this research.

\section{References}

Camacho MdR, Phillipson JD, Croft SL, Solis PN, Marshall SJ, Ghazanfar SA. Screening of plant extracts for antiprotozoal and cytotoxic activities. J Ethnopharmacol. 2003; 89: 185-91.

Chan-Bacab MJ, Peña-Rodríguez LM. Plant natural products with leishmanicidal activity. Nat Prod Rep. 2001; 18: 674-88.

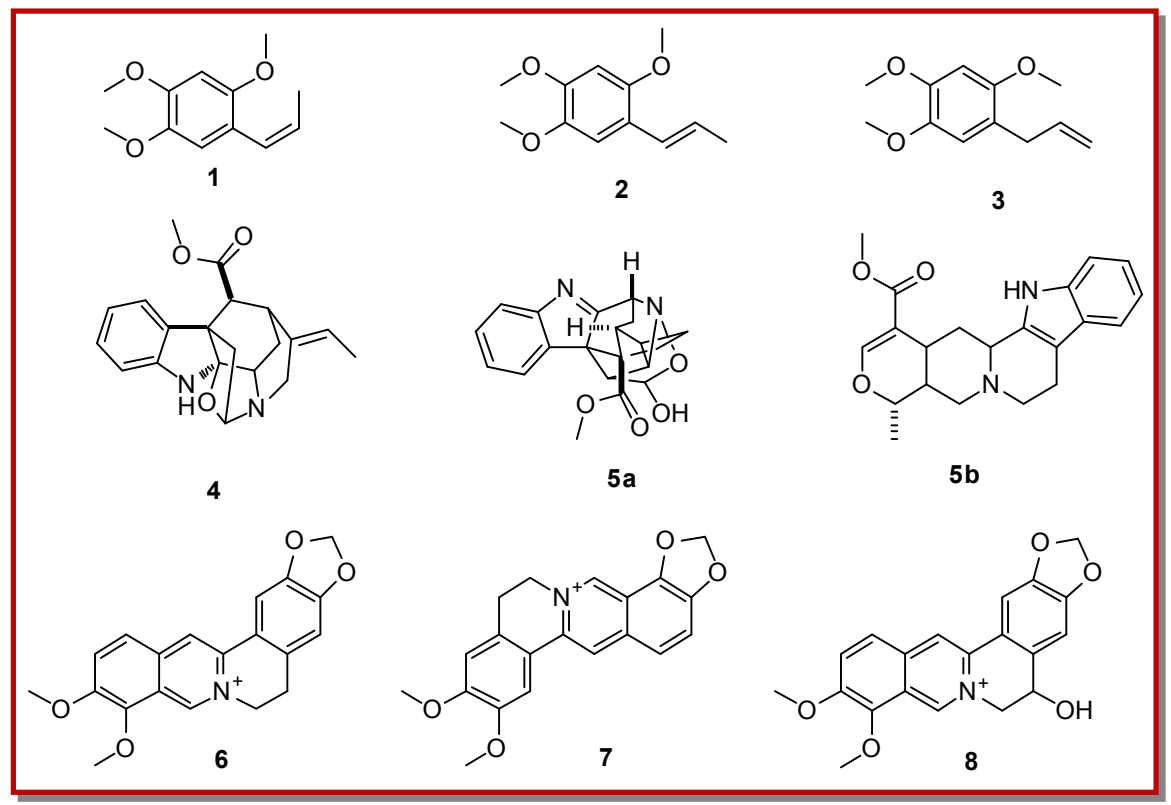

Figure 2: The structures of the compounds present in the active extracts as indicated by LC-MS analysis 
Croft SL, Sundar S, Fairlamb AH. Drug resistance in leishmaniasis. Clin Microbiol Rev. 2006; 19: 111-26.

de Albuquerque Melo GM, Silva MC, Guimaraes TP, Pinheiro KM, da Matta CB, de Queiroz AC, Pivatto M, Bolzani Vda S, Alexandre-Moreira Ms, Viegas C Jr. Leishmanicidal activity of the crude extract, fractions and major piperidine alkaloids from the flowers of Senna spectabilis. Phytomedicine 2014; 21:
277-81.

Mossman T. Rapid colorimetric assay for cellular growth and survival: Application to proliferation and cytotoxicity assays. J Immunol Methods. 1983; 65: 55-63.

Rocha LG, Almeida JRGS, Macedo RO, Barbosa-Filho, JM. A review of natural products with antileishmanial activity. Phytomedicine 2005; 12: 514-35. 